\title{
Western health practitioners' view about African traditional health practitioners' treatment and care of people living with HIV/AIDS ${ }^{1}$
}

\author{
JV Summerton, PhD \\ Researcher, Centre for Health Systems Research \& Development, University of the Free State
}

\section{Keywords:}

HIV, western health practitioners, traditional medicine

1 This paper is based on a study conducted for purposes of a doctoral thesis entitled "The role of practitioners of traditional medicine in the treatment, care and support of people living with HIV/AIDS".

\section{Correspondence address:}

\section{Joy Violet Summerton}

Centre for Health Systems Research \& Development

University of the Free State

P O Box 339

Internal Box 39

Bloemfontein, 9300

Tel: (051) 401-2181

Fax: (05) 444-5011

E-mail: summerj.hum@mail.uovs.ac.za

\section{Abstract: Curationis 29(3): 15-23}

African traditional health practitioners are an important source of health care for many South Africans. Thus, they are a health resource in this society. However, the integration of traditional health practitioners into the mainstream of health care is a complex process. Various factors contribute to this complexity, including the skepticism and reservation with which some western health practitioners view traditional health practitioners.

This paper highlights the perceived strengths and weaknesses of the traditional healing system for people living with HIV/AIDS, as perceived by western health practitioners. The use of traditional practitioners as a choice of health care is attributed to both the strengths and weaknesses of this system of health care. The strength of the traditional healing system is in its sharing of the worldview and belief system of its users, it being an alternative to an inefficient western health care system (official system), privacy and absence of time limitations per consultation, treating patients psychologically, and scientifically unexplained physiological relief of the symptoms of specific illnesses.

The perceived weaknesses of the traditional healing system include harmful treatment regimens, especially for people living with HIV/AIDS; prolonging the seeking of appropriate health care when traditional remedies fail to produce the desired effect; destroying interpersonal relationships of people living with HIV/AIDS through witchcraft accusations; psychological torment caused by the belief that HIV/AIDS can be cured by traditional remedies/intervention; and increasing the workload of western practitioners who are requested by patients to conduct multiple HIV tests after undergoing various traditional treatment regimens to cure HIV/AIDS.

It is recommended that traditional practitioners be encouraged to adapt harmful traditional healing practices to the benefit of their patients in a non-judgemental and non-critical manner. In addition, joint workshops should be conducted with traditional and westem practitioners to demystify traditional healing practices. 


\section{Background and introduction}

In societies which contain both traditional and western health care systems, the western health care system is, more often than not, the official and perceived superior of the two systems. It receives greater recognition in the professional sector than the traditional healing system, despite the acceptance of the latter system by a significantly large proportion of populations in developing countries. In South Africa, an estimated $70-85 \%$ of the population uses African traditional medicines to help meet their health care needs and approximately $60 \%$ of South African babies are delivered by traditional birth attendants (Abdool Karim, Ziqubu-Page \& Arendse 1994: 3; International Council of Nurses 2002: 1; Munk 1996: 7; Njanji 1999: 1; WHO 2002:1). The high utilisation rate of traditional medicine in developing countries may be attributed to (i) its historic accessibility and affordability in comparison to western medicine, and (ii) it being firmly embedded within wider belief systems (WHO 2002:2).

A large proportion of South Africans, both rural and urban, hold strong traditional cultural beliefs and practices, which influence their reactions to illness. According to Rukobo (1992: 5), it is the belief system that determines views of health, illness and disease. In African traditional societies the view of the world is one in which all elements of society are linked and functionally integrated. Consequently, medicine, illness, disease and death are understood within the context of religion and sometimes myth and mysticism. In the conception of illness there is a basic distinction between theories of natural and supernatural causation, which forms the comerstone of traditional cosmological, religion, social and moral worldviews of health and illness (Abdool Karim et al. 1994: 6). In the context of biomedicine, when an individual becomes ill, the question of causation pertains to 'what' caused the illness and 'how' it was caused. The traditional African worldview of causation believes that, in addition, the question of 'who' caused it and 'why', must also be addressed. This is an essential part of the healing process. As a result, any form of treatment/therapy given without this understanding may confuse the patient, thus compromising the treatment's effectiveness and acceptability (Abdool Karim et al. 1994: 6 ). The medication given by a traditional health practitioner may not alleviate the symptoms of illness, but the reassurance and the psychological effect of the consultation on the patient might play a vital role in restoring the patient's overall wellness. Similarly, the medication given by the western health practitioner may not provide psychological and spiritual comfort, but may alleviate the physical discomfort of illness. These aspects indicate the interdependent and complementary role that biomedicine and traditional healing play in the healing process.

Despite this interdependency between the traditional and western health care systems, efforts to include traditional health practitioners in the official health care system appear to be more advanced in other African countries, such as Uganda and Tanzania, than in South Africa. Considering that health services in South Africa still reflect the injustices and irrationality of apartheid. South Africa requires the provision of equitable health care which should be guided by the aspirations of the population, and the principles which reflect Traditional Health Care and the Primary Health Care Approach adopted by the World Health Organization (WHO) and United Nations Children's Fund (UNICEF) at Alma-Ata in 1978 (Rakolota 1992: 3; WHO 1978: 2). The Alma-Ata Declaration emanates from the International Conference on Primary Health Care, which took place in September 1978 to express the need for urgent action by all governments, health and development workers, as well as the world community, to protect and promote the health of all people worldwide. It specifically stated that the mobilisation of traditional medicines would be the only way in which health for all could be a reality. Many other organisations and government agencies have also called for closer collaboration between traditional and western medicine throughout the past decade. The African Union (AU), for one, declared the period 2001-2010 as the Decade of African Traditional Medicine, and the New Partnership for Africa's Development (NEPAD) has noted traditional medicine as an important strategy in its Plan (African Union 2001: 2; NEPAD 2001: 31). Despite these declarations, legalising and officially recognising traditional health practitioners have been characteristically slow in the legislatures of African countries (Gbodossou, Floyd \& Katy s.a.: 4).

Before the election of the democratic government of South Africa in 1994, the African National Congress (ANC) made a proposition in its health plan. It proposed to include traditional health practitioners as an integral recognised part of health care in South Africa. It claimed that consumers would be granted the right to consult a provider of their choice for their health care, and that legislation would be changed to facilitate controlled use of traditional practitioners (ANC 1994: 33). The White Paper for the Transformation of the Health System in South Africa 1997 states: "the regulation and control of traditional healers should be investigated for their legal empowerment. Criteria outlining standards of practice and an ethical code of conduct for traditional practitioners should be developed to facilitate their registration" (Ministry of Health 1997:34). In 2004, the Traditional Health Practitioners Bill for South Africa was unanimously approved in Parliament and was enacted on 11 February 2005 (Republic of South Africa 2005).

South Africa finds itself in the wake of the devastating effects of the HIV/AIDS epidemic on all its sectors. After much debate and controversy surrounding the provision of quality health care to individuals living with HIV/AIDS, the South African Government finally took up the challenge of including antiretroviral therapy as part of providing comprehensive health care services. However, on the one hand, South Africa finds itself in a disadvantaged position to provide access for many AIDS patients to life-long antiretroviral therapy due to the high costs associated with this treatment. South Africa, therefore, has to resort to other means to reduce AIDSrelated morbidity and mortality among the population that lives below the poverty line and is plagued by malnutrition and other factors that exacerbate the onset of full-blown AIDS. On the other hand, health care is belief-sensitive. The African belief system and the western belief system, stand divided in their interpretation of illness and health. Therefore, the South African Government bears the responsibility of accommodating the health care needs of all South Africans in a non-biased manner. This includes those individuals who opt for the traditional healing system 
as their choice of health care.

South Africa, although at a less rapid pace compared with other African countries such as Uganda and Tanzania, also portrays signs of moving towards integrating traditional health practitioners into certain primary health care programmes, rather than the coexistence of the two systems. The Operational Plan for Comprehensive HIV and AIDS Care, Management and Treatment for South Africa 2003 (Operational Plan) (Department of Health 2003: 84) refers to traditional health practitioners as an essential and irreplaceable component of the continuum of care developed for the HIV/AIDS care and treatment programme in South Africa. Furthermore, the operational plan acknowledges the importance of the role played by traditional health practitioners in treating and caring for people living with HIV/ AIDS (PWAs), especially in the expanding of the official HIV/AIDS care and treatment programme throughout the country. The South African Government has reiterated the need to integrate traditional health practitioners into the national health care system. However, a lack of clearly delineated policy guidelines for collaboration and translating policy into practice in many instances undermine Government efforts. The South African Government needs to (i) research patients' needs and perceived benefits/risks of traditional health care; (ii) monitor the implementation of policies and guidelines related to the traditional health care system; and (iii) monitor the collaboration between traditional and western health practitioners.

The utilisation of African traditional medicines by an estimated $70-85 \%$ (WHO 2002: 1) of South Africans, and the proposed high costs associated with providing equitable antiretroviral therapy in the midst of an HIV/AIDS epidemic, point towards an urgent need for a more vigorous approach towards the inclusion of traditional health practitioners in the official health care system of the country. The AIDS epidemic in South Africa continues to threaten social and economic developments through its adverse effects. Adversities include shortened life expectancy, burdened public health care services, poor quality of life, and escalating number of AIDS orphans due to maternal and paternal AIDS-related deaths. Hence, the traditional healing system is an important

\section{Figure 1 Map of research area - Eastern Cape Province}

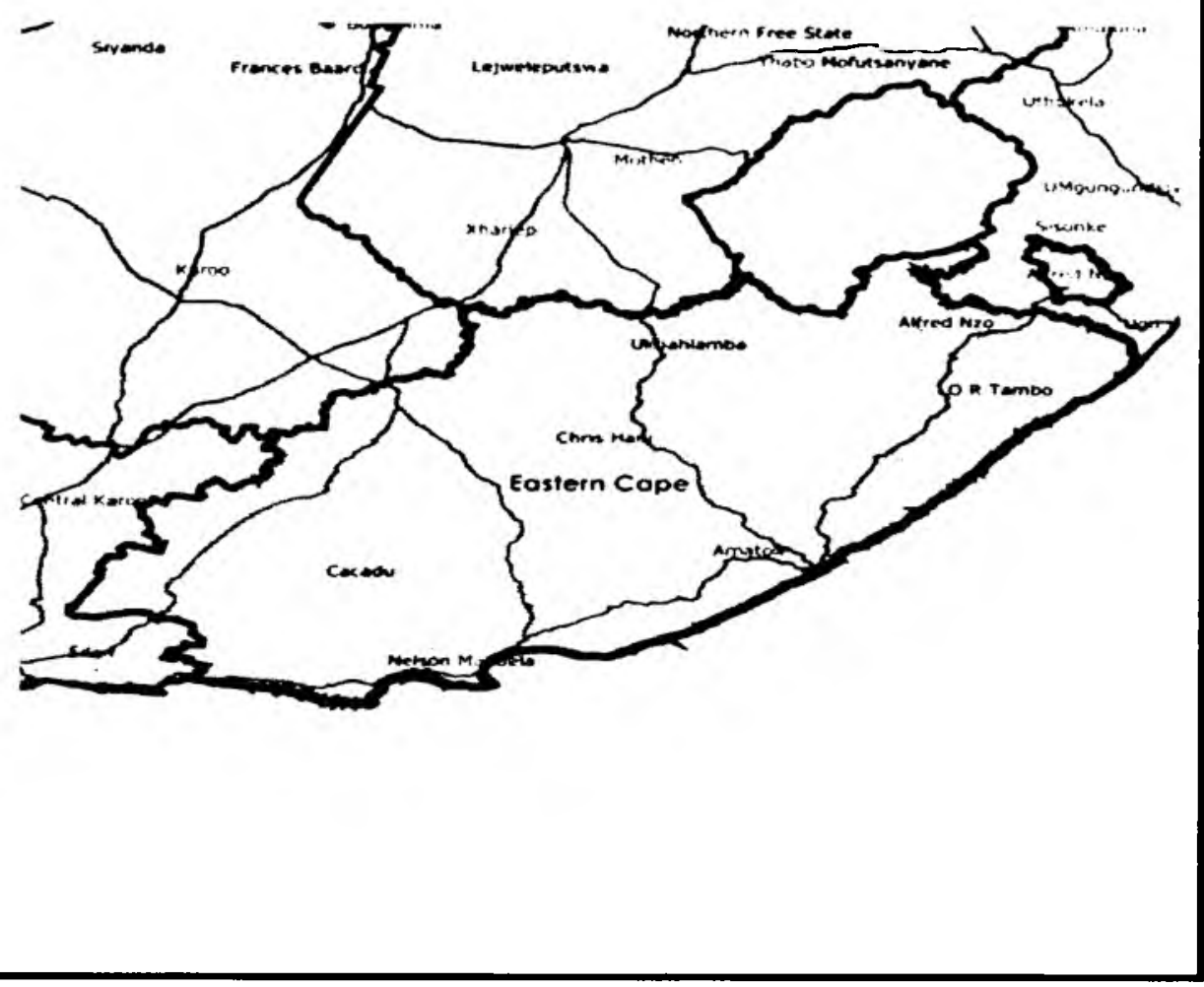

health resource in South Africa, and efforts to position it in the mainstream of health care are vital in responding to national health care challenges.

Various factors impede the effective collaboration between traditional and western health practitioners in South Africa. Hammond-Tooke (1989: 185) attributes the difficulty in integrating western and traditional medicine to the prejudicial notion that traditional African beliefs and practices are 'primitive' and 'savage'. Gumede (1990: 153) reiterates this notion by pointing out that western health practitioners' critical view of traditional medicine is based on notions which perceive traditional health practitioners as posing a danger to the health of their patients. The skepticism with which western practitioners view traditional healing and practitioners thereof, is not wholly unjustified. Various factors contribute towards such skepticism, including the lack of knowledge among western practitioners about traditional theories of disease and health, mysticism surrounding traditional medicines (content), and harmful traditional healing practices and medicines. However, these negative factors associated with the traditional health care system might not justify the exclusion of traditional health practitioners from the realm of health care in general, and priority programmes such as HIV/AIDS. It is to this end that this paper explores the views of western health practitioners pertaining to the benevolent and malevolent functions of traditional practitioners as health care providers, with specific reference to HIV/ AIDS treatment and care. Hence, this paper addresses the value and weaknesses of the traditional health care system as perceived by western health practitioners.

\section{Research approach, methodology and participants}

Qualitative research methods were applied due to the nature of the study, namely, to explore the strengths and weakness of the traditional health care system as perceived by western health practitioners. Qualitative research methods, in relation to quantitative methods, are flexible in that they allow the researcher to develop concepts during data collection. Hence, as data are collected the researcher may reflect on the data collection process and develop new ideas. This ensures continual interaction between data and existing ideas during data collection. In other words, as the researcher gathers data, he/ 


\section{Figure 2 Map pf research area - Amatole Distrct Municipality (DC12)}

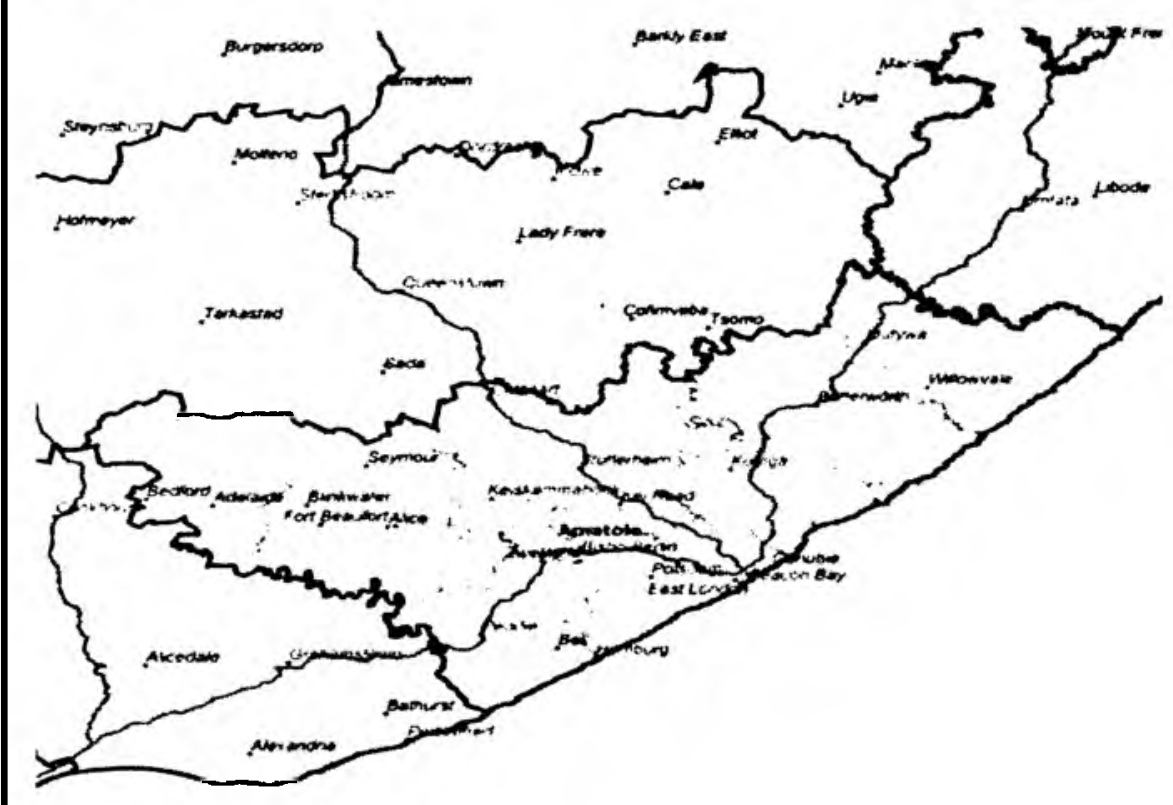

she uses some pre-existing constructs to assist in data collection, and then incorporates the existing ideas with new ideas that are developed from the data (Neuman 2000: 46-48).

The research participants were selected from Buffalo City Local Service Area (LSA)/Local Municipality (cf. figure 3 ) in the Amatole District Municipality (cf. figure 2) of the Eastern Cape Province (cf. figure 1) (Municipal Demarcation Board 2003).

Purposive and sequential sampling were used to select 23 western health practitioners from primary health care facilities (community health centres/day hospitals and fixed clinics) in two urban residential areas in East London, namely Duncan Village and Gompo Town. Purposive sampling was most appropriate since the group of respondents was selected according to their involvement in treating and caring for PWAs at a primary health care level. The researcher, with the assistance of representatives of the Buffalo City LSA management, selected individuals from various strata of primary health care, namely professional nurses, HIV/AIDS counsellors, home-based caregivers and general practitioners. Selection of respondents continued up until a point of data saturation was reached, namely 23 interviews (sequential sampling). Table 1 provides a profile of the respondents. The majority of the respondents were female (20 respondents).

A combination of semi-structured and indepth interviews, as well as direct observations were utilised to collect data (Laws, Harper \& Marcus 2003: 30-36). Utilising both semi-structured and unstructured interview techniques resulted in interview schedules that contained broad topic areas as well as specific probing questions. Also, the interview schedules allowed for questions to be added and omitted based on the responses of each interviewee, which guided the interview process. The interview schedules followed the structure for field research interviewing, namely they constituted three types of questions: descriptive, structural and contrast questions (Neuman 2000: 288293).

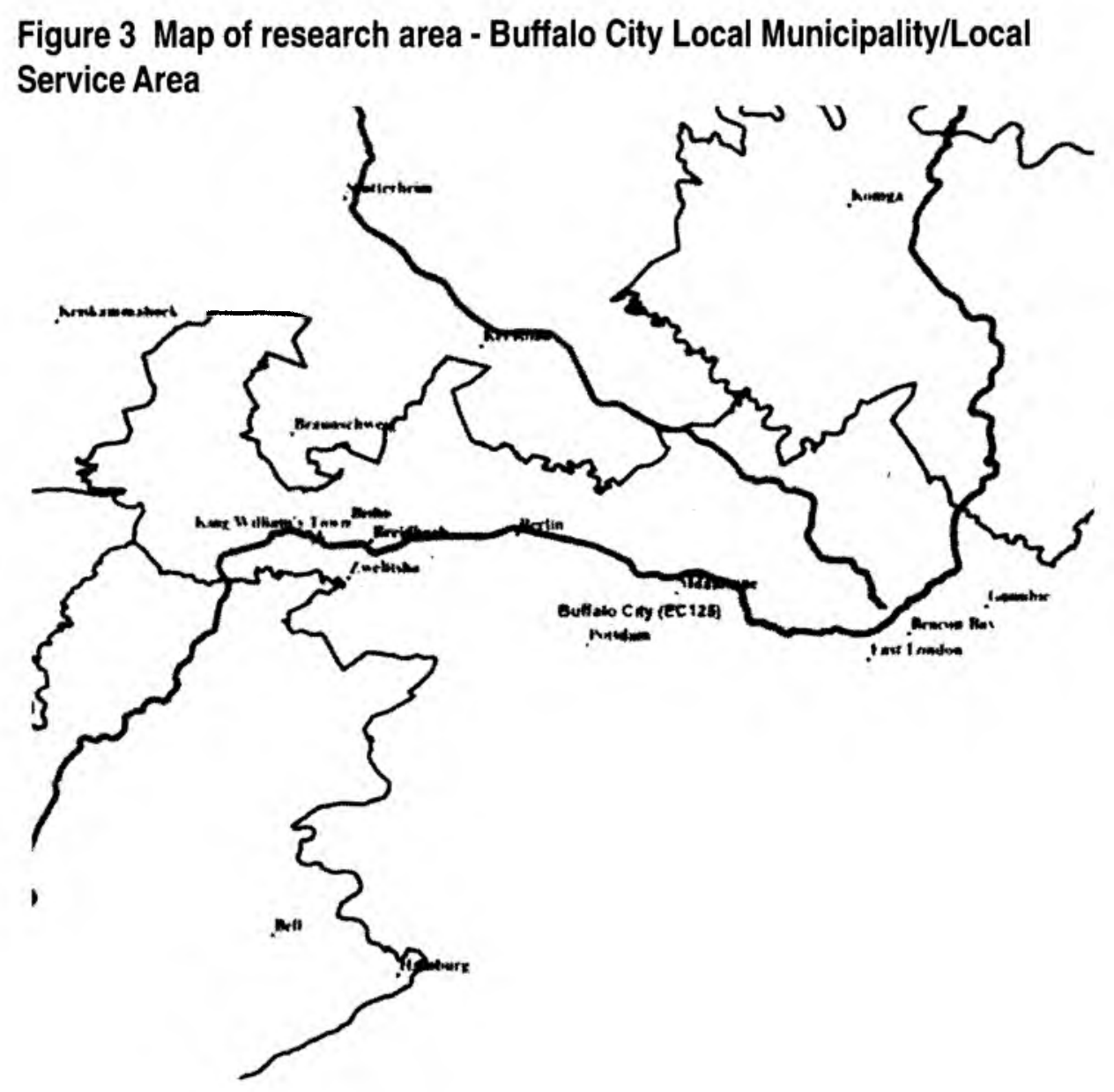


Table 1: Western health practitioners by category

\begin{tabular}{|l|l|}
\hline Category & Number \\
\hline General practitioner (doctor) & 6 \\
\hline Professional nurse & 7 \\
\hline HIV/AIDS counsellor & 5 \\
\hline Community health worker & 5 \\
\hline Total & $\mathbf{2 3}$ \\
\hline
\end{tabular}

Essentially, the first three interviews with western health practitioners mainly comprised descriptive questions. After transcribing the interviews and systematising the data, the researcher adapted the interview schedules by increasing the number of structural questions based on emergent concepts from the first three interviews. This also served as verification of data. Thereafter contrast questions were added to further verify data among western health practitioners. Therefore, the interview schedules developed prior to data collection were administered loosely, where the sequence of topics, type of probing questions, and the structure of questions were determined by the responses of respondents. In addition new issues that transpired from each interview, and that were relevant to the research objectives, were included in subsequent interviews. Hence, the interview schedules were adapted in accordance with the progression of each interview.

Appointments were made prior to interviews as far as possible. Where such prior arrangement was not possible, interviews were conducted as soon as a respondent was located. Although appointments were made prior to interviews, difficulty was experienced in finding an appropriate time to conduct interviews with some of the staff, due to their high workloads. This was especially the case with general practitioners and nurses, as compared to the other categories of health practitioners. The least busy days (minimal expected workloads), and times were selected for conducting interviews, in order to cause the least disruption to the operation of the health care facilities, as well as the respondents' work schedules. This tactic proved successful, although some interviews were rescheduled. The duration of the interviews varied between one hour and two hours.

\section{Data Analysis}

Qualitative data analysis techniques were utilised, namely grounded theory (Babbie \& Mouton 2001: 498). It entailed organising the transcribed data into categories on the basis of conceptual themes. According to Neumen (2000:78), concept formulation is an integral part of data analysis and it begins during data collection. New concepts were, thus, developed and conceptual definitions formulated throughout data collection. Open coding was utilised to condense the large volume of data into conceptual themes (Babbie \& Mouton 2001: 499-500; Strauss 1987: 56-63). This entailed coding the data by closely scrutinizing the transcribed material, line by line and word by word, and extrapolating the essence of words, phrases and sentences so as to attach a relevant code. Furthermore, associated subcategories which were reflected either in the same sentence, or other sentences within the same or different interview were also coded. Initially the codes were crude. However, as the process of scrutinisation of transcripts continued, so codes became saturate and, thus, modified and elaborated. Thematic codes were, therefore, created and changed throughout the process of analysis. It is important that codes do not remain mere descriptions, but rather to be analytical by giving meaning to data. The data were summarised into the created conceptual themes. Findings were inferred from the summarised data, and quotations were used to highlight, substantiate and illustrate points.

\section{Views of western health practitioners}

Discussion of data focuses on three main themes, namely reasons for the high utilisation of traditional practitioners, the value of traditional healing, and the weaknesses/disadvantages of the traditional health care system. Although the attitudes and views expressed by western health practitioners differed from one individual to another, similarities in views were evident within, as well as between categories of respondents. Reference is made to such similarities and differences where relevant, and substantiated by direct quotations from respondents.

\section{Reasons for consulting traditional practitioners}

Western practitioners had various notions as to why they believed patients opted to consult traditional practitioners, irrespective of the accessibility of western health care facilities and practitioners. The following reasons are attributed to individuals utilising the services of traditional practitioners:

- Belief and trust in traditional practitioners;

- Historical accessibility of traditional practitioners;

- $\quad$ Lack of sufficient knowledge and understanding about HIV/ AIDS among patients;

- $\quad$ Privacy offered by traditional practitioners;

- $\quad$ Negative attitudes of western practitioners towards patients;

- $\quad$ Promise of a traditional cure for AIDS;

- Inefficient western health care referral system; and

- $\quad$ Shared worldview and traditional theories of disease causation between patient and traditional health practitioner.

Two of the aforementioned attributes to the utilisation of traditional practitioners were more prominent than others. These are further elaborated upon.

\section{A traditional cure for HIV/AIDS}

Western practitioners are of the opinion that PWAs are mainly lured to the consultation rooms of traditional practitioners because of the hope of a "miracle cure", as opposed to the "no cure" message reiterated in the corridors of western health care facilities. On the one hand, traditional practitioners believe that illnesses are curable through the correct diagnosis of the cause, often associated with supernatural phenomena. This belief leaves room for hope that, with the correct diagnosis of the cause of HIV/ AIDS, one may be cured. On the other hand, western practitioners unequivocally and unambiguously state that HIV/AIDS still remains incurable. Faced with two contradictory views about HIV/AIDS, PWAs are believed to opt for the practitioner that offers some hope that they will return to their normal 
state of health and become HIV-negative.

\section{Inefficient western health care system}

The reported absence of an intermediary level of care (district hospital) between primary health care clinics/community health centres and the tertiary hospital in Buffalo City, is perceived to contribute to the influx of patients to traditional practitioners. In this event, traditional health practitioners are perceived by patients as the only other alternate health care providers. According to national referral policies, the typical referral chain consists of three levels of care, namely primary (clinic/community health centre/ day hospital), secondary (district hospital) and tertiary (provincial hospital). The reported absence of a district hospital in Buffalo City interrupts the referral chain, with negative repercussions for patients. In other words, patients who suffer from an HIV/ AIDS-related illness, but cannot receive the appropriate care and treatment at a primary health care facility, are typically not referred to the tertiary hospital, because they will reportedly not receive the necessary treatment and care due to their HIV status. Therefore, failure to receive appropriate treatment and care from the western health care system, often results in patients choosing to go to traditional practitioners as their next best option.

The limited resources available to primary health care practitioners in the absence of an intermediary referral facility (between primary health care facilities and the provincial hospital), diminishes a patient's health care options, thus, driving patients to traditional practitioners.

The negative attitudes of western practitioners, privacy and unlimited time offered by traditional practitioners per consultation were reiterated as contributing factors to the high utilisation rate of traditional practitioners.

The following response serves as example in point:

"Patients get to traditional healers and find that the atmosphere is so conducive and they feel comfortable. If we (western practitioners) could change our attitudes ... how we treat our people ... the way we speak to them, we can win society in that way".

Traditional healing: beneficial or

\section{not?}

Western practitioners are divided in their stance on whether or not traditional healing has any benefits, as well as on the nature of such benefits. By and large, the benefits of traditional healing are perceived to be directly proportionate to an individual's belief in traditional healing, more especially in the theories of disease causation upon which the traditional healing system is founded. Some western practitioners believe that traditional healing is beneficial only in addressing psychosomatic and psychological aspects of illness, as opposed to providing scientifically significant physiological changes in the health of patients. This notion is evident in the following responses:

"Definitely, psychologically it does help a lot, because clients get the attention from a traditional healer that they want. That in itself is of value, in addition to their little concoctions. There is something called the placebo effect which means something will always work as long as you believe that it does". "It's what you believe in that heals you. I believe that panado works, but my husband will say that 1 should not give him panado, because it doesn't work". "People believe in traditional healing. It's all about psychology. I am sure that if we could come together and for there to be intersectoral collaboration, not so many people will die, because they will get more comprehensive help".

Other practitioners believe that traditional healing has the ability to affect beneficial physiological changes. This notion is based on scientifically unexplained physiological relief of the symptoms of illness in some patients. At the same time, some western practitioners are of the opinion that traditional medicine is more effective in treating certain illnesses, such as cancer, than western medicine. The following responses are examples in point:

"You will find that from time to time you meet a patient who will tell you that they had certain symptoms and that they went to a traditional healer and this and this happened. And you cannot explain it either, but you will find that this person did get a cure for whatever he/she had. I even remember a patient of mine who had breast cancer. She said that she had been to doctors, hospitals ... wherever, wherever, and they couldn't see anything wrong with her. She went to a traditional healer who diagnosed her with breast cancer and treated her. When she came to me ... not that the traditional healer had cured her, but she had less severe symptoms ... she had a sepsis and this big ulcer which was evident that she had cancer".

What I see is that these herbs that they claim cure HIV/AIDS are in actual fact boosting the immune system, because patients come to them weak and frail, and then they become stronger after getting treatment from them. However, they give them (patients) false hope by making them think that they are cured". "In my view, cancer is mostly treated best by traditional healers, which is why we should collaborate with them. Sometimes, western doctors do not see what is wrong with a patient. They will tell you that they have looked and looked and looked, but cannot see anything wrong. But, when that person goes to a traditional healer, the healer will diagnose him/her with cancer and treat them thereafter. This does happen sometimes. This is why they need to get together and collaborate"

In summary, traditional healing is seen as beneficial only in as far as it provides some sort of psychological relief for patients who believe in traditional healing, more especially in the theories of causation pertaining to illness and health, which form the backbone of the traditional healing system. However, observations have been made, which point towards evidence of immune boosting effects of traditional medicine, which have not been clinically substantiated.

\section{Disadvantages of traditional healing}

A lack of sufficient knowledge about HIV/AIDS amongst both traditional practitioners and PWAs who consult traditional practitioners appears to be the most salient problem associated with the traditional healing system in Buffalo City. Harmful treatment regimens and delaying seeking appropriate health care when prescribed traditional medicines do not produce the desired results are two of the most severe consequences of insufficient knowledge about HIV/AIDS among traditional practitioners. One other negative consequence is the experience of psychological torment when clients are made to believe that they can be cured through traditional healing. These consequences lead to an increase in the workload of primary health care practitioners, and also destroy 
interpersonal relationships of patients who need a strong social support system.

\section{Harmful treatment regimens}

The typical traditional treatment regimen for patients who present with an HIV/ AIDS-related illness (diagnosed as HIVpositive either by a western practitioner, or traditional practitioner), is the use of enemas and inducing vomiting, as reiterated in the following response: "There are a group of people who believe very much in traditional healers, in so much that they undermine western medicine. They will say that traditional medicines will cure them and they will be healed, because those medicines are good and they are strong because they make them vomit and have diarrhoea, which will excrete the illness in them". The danger of this treatment method is that it exacerbates dehydration in already emaciated patients, possibly causing more harm than good. It is also reported that some of the traditional medicines used by traditional practitioners further destroy the immune system of HIV/AIDS patients due to the strength of their reaction. Some traditional practitioners are also accused of discouraging patients from using western medicines once they have started traditional treatment. As a result, the patient's health deteriorates to the extent that either the traditional practitioner refers the patient to a western health care facility, or the patient refers himself/herself to such a facility as a last resort. This referral often takes place once the patient is in the final stages of illness when the chances of successful treatment have been minimised drastically. This problem is best expressed by the following responses:

"They keep their patients even while their patients are deteriorating, instead of bringing them to clinics or hospitals, until the patient dies. Or else, they only bring the patient to a clinic or hospital once the patient is obviously dying".

"I've seen patients who have been emaciated badly, and when I ask them where they have been, they say that they were in this sangoma's hut for the past two months and now they have given up. They come here as a last resort. Patients who come here from traditional healers arrive here terminal".

"Some children who are diagnosed as $H I V$-positive are under-age. Because they are under-age, and many parents are still from the old school of thought where traditional healers are believed to be the best source of help, they end up taking their children to traditional healers first, and that is where the children start experiencing problems. What happens is that by the time the parents find out that the children are $H I V$-positive, it is already too late. By then, time has gone by and the children's health has deteriorated too much".

\section{Delaying seeking appropriate health care}

Prolonging seeking appropriate health care when traditional treatment does not produce the desired effect, can be perceived as a manifestation of a sense of denial of one's HIV status. This sense of denial is reportedly sustained and nurtured by traditional practitioners' lack of sufficient knowledge of the complexity of HIV/AIDS. A sense of denial of one's HIV status creates room for the belief that one will return to one's natural state of health (absence of disease). This belief is supported and fuelled by the notion held by many traditional practitioners, namely that all recurrent illnesses/ diseases have a supernatural cause. Based on the correct diagnosis and, thus, adherence to the appropriate treatment (corrective action), all diseases/illnesses are curable. The following responses are indicative of a sense of denial of HIV status by PWAs:

"I know of a professional nurse who died at a traditional healer. She was my friend. For a professional nurse to run to a traditional healer means that they are in a state of denial where they do not want to admit that they are HIVpositive. They deny it up to the last end".

"Sometimes patients are diagnosed as $H I V$-positive, but they do not even start to take the treatment and health/ nutritional education that we give them after their diagnosis. Instead, they believe that they do not have HIV/AIDS, Instead, they see it as a sign that they should perform a ceremony to their ancestors - 'isiko'. Or else they say that they do not have a white (western) illness, but a family illness (traditional illness). That is why I say that patients run to herbalists, because they are in denial about their HIV status".

Also problematic, and related to traditional healing, is denial of the implications of being HIV-positive, namely having to live with the illness for the rest of one's life. Traditional practitioners who propagate that all illnesses can be cured through the appropriate corrective action, provide a scapegoat for PWAs who are not willing to accept a life-long illness.

\section{Increased workloads and negative psychological effects}

The adversity of claims of traditional cures for HIV/AIDS is evident in the number of patients who reportedly insist on multiple HIV tests after undergoing various traditional treatments to cure HIV/AIDS. In addition to increasing the workload of western practitioners who have to repeatedly counsel and test the same patients, as insisted upon by the patients, and as advised by traditional practitioners consulted, the psychological turmoil and emotional torment experienced by the patients upon receiving the same HIV-positive result after each test remains unparalleled. The following statement is such a case in point: "For example, a person will be tested positive the first time, then they return for another test and again for a third test. When you ask them why they are repeating the test, they will tell you that they are testing repeatedly because they have heard that there is a specific herbalist that cures HIV/AID. So, they decided to go themselves. They will tell you that when they went to him, they told him that they were tested positive and even showed him their results. Now they have to come back for another test to confirm that they are cured, because they have completed his treatment. When you test them, the results come back positive again".

\section{Destroying interpersonal relations}

Traditional practitioners are also said to compound volatile interpersonal relations within households, and between households in communities, by attributing the symptoms of HIV/AIDS to witchcraft or malevolent magic. In the case where witchcraft is the presumed cause of illness, there is typically an accused who is often someone known by the ill person. During consultation with a traditional practitioner, the identity of the accused is either revealed descriptively, or through a course of events which implicate a specific individual. Attributing the cause of illness to witchcraft only serves the purpose of aggravating the emotional and psychological repercussions of HIV/ AIDS, by straining relations between the person living with HIV/AIDS and his/her relatives, friends, neighbours and colleagues, who are usually implicated in the process of identifying the cause of 
illness. This adverse effect of traditional healing is best described by the following statement: "Instead of people supporting each other, they end up looking at each other suspiciously, because they believe that some people bewitch others". This finding is substantiated by literature about the interpretation of HIV/AIDS by traditional practitioners. Very often, illness is believed to be a manifestation of witchcraft, and rituals are performed to cast away evil spirits. This results in strained human relations in communities, since neighbours and relatives are named as witches (Shabalala 2003: 2).

In essence, the acclaimed physical and psychological benefits of traditional healing for individuals who utilise this health care system are matched with grave consequences. The identified negative repercussions of traditional healing are indicative of weaknesses in the traditional healing system, which often outweigh and ultimately undermine the benefits of this system. It is, therefore, imperative that these weaknesses are addressed urgently as a means to improve the standard and safety of traditional health care for those individuals who, by choice, utilise this health care system.

\section{Recommendations}

Formal deliberations about the relationship between traditional healing practices and harmful reactions thereto, especially for people living with HIV/ AIDS, should be conducted. These discussions should focus specifically on the relationship between the immune system of people living with HIV/AIDS, enemas and vomiting. Deliberations should be interactive and culture-specific as opposed to being authoritative and biomedically-based. Traditional practitioners should be encouraged to adapt harmful traditional healing practices to the benefit of their patients in a non-judgemental and non-critical manner. Care should also be taken to avoid prescribing western practices as the superior and more effective form of treating people living with HIV/AIDS. This approach will merely deter traditional practitioners from taking cognisance of any useful information that will benefit their patients.

\section{Conclusion}

The ravaging impact of the HIV/AIDS epidemic on societies, especially in developing countries, has evoked a renewed urgency to consolidate all available resources to address the health needs of individuals living with HIV and AIDS. One such resource in resourceridden countries is the traditional healing system. In general, western health practitioners see value in traditional healing. Value is attributed to the ability of traditional practitioners to treat patients psychologically and relieve psychosomatic symptoms. However, the harmful practices of traditional practitioners, especially pertaining to the treatment regimens for patients that present with HIV-related illnesses, and the belief that HIV/AIDS can be cured, undermine the perceived effectiveness of the traditional healing sector amongst western practitioners.

It is of the utmost importance that the weaknesses of the traditional healing system do not deter efforts towards integration of the two systems of health. These efforts are essential to improve the quality and accessibility of health care for a significant proportion of the South African population which utilise traditional medicines. Furthermore, the critical view of western practitioners towards traditional practitioners needs to be addressed in order to promote effective collaboration between the two groups of practitioners. After all, the South African traditional healing sector has survived illegality and criticism from the western health fraternity for decades. The fact that traditional practitioners are flourishing all over the country is evidence of the continuous need for their services amongst South Africans. Were there no need for traditional healing, traditional practitioners would not exist.

\section{Limitations}

Although the findings of the research undertaken may not be generalised due to the non-probability sampling methods applied and small sample size (23 respondents), they serve to inform interventions and policies aimed at improving the accessibility and quality of health care for people living with HIV/ AIDS.

\section{REFERENCES}

ABDOOLKARIM,SS; ZIQUBU-PAGE, T \& ARENDSE, $R$ 1994: Bridging the gap: Potential for a Health Care Partnership between African Traditional Healers and Biomedical Personnel in
South Africa. Pretoria: Medical Research Council (South Africa).

AFRICAN NATIONAL CONGRESS (ANC) 1994: A National Health Plan for South Africa. Pretoria: African National Congress.

AFRICAN UNION (AU) 2001: Decisions and Declarations. (Thirty-seventh Ordinary Session/Fifth Ordinary Session of the Assembly of Heads of State and Government: 9-11 July 2001: Lusaka: Zambia).

BABBIE, E \& MOUTON, J 2001: The practice of social research. The South African edition. Cape Town: Oxford University Press Southern Africa.

CHI, C 1994: Integrating traditional medicine into modern health care systems: Examining the role of Chinese medicine in Taiwan. Social Science \& Medicine, 49(3): 307-321.

DEPARTMENT OF HEALTH (South Africa) 2003: Operational plan for comprehensive HIV and AIDS care, management and treatment for South Africa. Pretoria: Department of Health.

GBODOSSOU, EVA; FLOYD, VD \& KATY, CI s.a: AIDS in Africa: Scenarios for the Future. The role of traditional medicine in Africa's fight against HIVI AIDS. [Internet] PROMETRA. Available from:<http://www.prometra.org/ Document s/A I D in AfricaScenariofortheFuture.pdf $>$ [Accessed on 23 August 2005].

GUMEDE, MV 1990: Traditional Healers: a medical doctor's perspective. Johannesburg: Blackshaws.

HAMMOND-TOOKE, D 1989: Rituals and medicines: indigenous healing in South Africa. Johannesburg: Ad Donker.

INTERNATIONAL COUNCIL OF NURSES 2002: Marrying the modern and traditional in health practices. Press Release. Geneva: International Council of Nurses.

LAWS, S; HARPER, C \& MARCUS, $R$ 2003: Research for Development. A practical guide. London: SAGE Publications.

MINISTRY OF HEALTH (South Africa) 1997: White Paper for the 
Transformation of the Health System in South Africa. Cape Town: Ministry of Health.

\section{MUNICIPALDEMARCATIONBOARD}

(South Africa) 2003: [Internet]. Available from: <http://www.demarcation.org.za> [Accessed on 02 September 2005].

MUNK, K 1996: Traditional disease aetiologies and HIV/AIDS among urban Zulu. AIDS Analysis Africa. 7(2): 7-12.

NEUMAN, WL 2000: Social Research Methods. Qualitative and Quantitative Approaches ( $4^{\text {th }}$ ed). Boston: Allan and Bacon.

NEPAD 2001: The New Partnership for Africa's Development. South Africa: NEPAD.

NJANJI, S 1999: AIDS-Africa-medicine: African traditional healers part of army to fight AIDS. [Internet] Agence-FrancePresse. Available from: <http:// www.aegis.com/news/afp/1999/ AF990956.html> [Accessed on 01 August 2003].

RAKOLOTA, T 1992: The role of the traditional medical practice in the provision of national health services. Traditional Health Care and Wild Life Consultants. (Paper presented at the Conference on Ethnomedicine and Health in the SADCC Region: 26-30 October 1992: Maseru Sun Cabanas: Lesotho).

REPUBLIC OFSOUTH AFRICA 2005: Traditional Health Practitioners Act, 2004. Government Gazette, 476(27275). Cape Town.

RUKOBO, AM 1992: The social context of traditional medicine in Zimbabwe. Institute of Development Studies: University of Zimbabwe. (Paper presented at the Conference on Ethnomedicine and Health in the SADCC Region: 26-30 October 1992: Maseru Sun Cabanas: Lesotho).

SHABALALA, Z 2003: HIV/AIDS - a challenge to the church in Africa. Available from: <http://www.elmmission.net/english/mitteilen/rtf_files/ shabalala.rtf $>$ [Accessed on 5 August 2003].

STRAUSS, AL 1987: Qualitative Analysis for Social Scientists. London: Cambridge University Press.
WORLD HEALTH ORGANIZATION (WHO) 1978: Declaration of Alma-Ata. (International conference on primary health care: 6-12 September 1978: AlmaAta).

WORLD HEALTH ORGANIZATION (WHO) 2002: WHO Traditional Medicine Strategy 2002-2005. Geneva: World Health Organization.

\section{Acknowledgements}

Prof HCJ van Rensburg (Centre for Health Systems Research \& Development, University of the Free State)

Prof C Ngwena (Department of Constitutional Law and Philosphy of Law, University of the Free State)

Prof E Pretorius (Faculty of Humanities, University of the Free State)

Eastern Cape Department of Health

Buffalo City Local Municipality

Ms Mtyeku (Eastern Cape Traditional Health Practitioners Coordinator)

Andrew Mellon Foundation 